\title{
YYPE VE PP PARÇALARDAKİ KALINTI GERİLMELERE ENJEKSİYON KALIPLAMA ŞARTLARININ ETKİLERİ
}

\author{
Şükran KATMER ${ }^{1}$, Çetin KARATAŞ ${ }^{2}$ \\ ${ }^{1}$ Yalova Üniversitesi, Yalova Meslek Yüksekokulu, Malzeme ve Malzeme İşleme Teknolojileri Bölümü Yalova \\ ${ }^{2}$ Gazi Üniversitesi, Teknoloji Fakültesi, İmalat Mühendisliği Bölümü, Teknikokullar Ankara \\ sukran.katmer@yalova.edu.tr, cetink@gazi.edu.tr
}

(Geliş/Received: 13.03.2014; Kabul/Accepted: 29.06.2015)

ÖZET

\begin{abstract}
$\mathrm{Bu}$ çalı̧̧mada enjeksiyon kalıplama şartlarının kalıplanmış plastik parçalardaki kalıntı gerilmelere ve çekme dayanımlarına etkileri araştırılmıştır. Altı kalıplama şartı (enjeksiyon basıncı, enjeksiyon sıcaklığı, kalıp sıcaklığı, ütüleme basıncı, ütüleme süresi ve soğutma süresi) ve her bir faktörün üç seviyesi çalışılmıştır. Deney sayısının azaltılması için Taguchi Deney Tasarımı kullanılmıştır. Dikdörtgen şekilli deney parçaları yüksek yoğunluklu polietilen (YYPE) ve polipropilen (PP) malzemelerden kalıplanmıştır. Kalıntı gerilmelerin ölçümü için katman kaldırma yöntemi kullanılmıştır. Kalıntı gerilme olarak YYPE'de 3,5 MPa, PP'de 0,6 MPa çekme kalıntı gerilmesi; YYPE'de -0,6 MPa, PP'de - 0,16 MPa basma kalıntı gerilmesi elde edilmiştir. Kalıntı gerilmeye YYPE parçalarda etkinlik sırasıyla, soğutma süresi, enjeksiyon sıcaklığı ve ütüleme basıncı etkili olurken, PP parçalarda ise, soğutma süresi, enjeksiyon sıcaklığı ve kalıp sıcaklığı etkili olmuştur.
\end{abstract}

Anahtar Kelimeler: Enjeksiyon kalıplama, kalıntı gerilme, çekme dayanımı, katman kaldırma tekniği, YYPE, PP, Taguchi deney tasarımı

\section{EFFECTS OF INJECTION MOLDING CONDITIONS ON RESIDUAL STRESS IN HDPE AND PP PARTS}

\begin{abstract}
This research examines effects of molding conditions on residual stress and tensile strength of injection molded plastic parts. Six factors (injection pressure, melt temperature, mold temperature, packing pressure, packing time and cooling time) and three levels of each factor were examined. Taguchi experimental setup was used to reduce the number of experiments. The rectangular shaped flat parts were molded using high density polyethylene (HDPE) and polypropylene (PP) samples. The layer removal technique was used to prediction of the residual stresses. Results show that the influential factors are cooling time, melt temperature and packing pressure on HDPE parts, and cooling time, melt temperature and mold temperature on PP parts.
\end{abstract}

Keywords: Injection molding, residual stress, tensile strength, layer removal technique, HDPE, PP, Taguchi's experimental design

\section{GİRIŞ (INTRODUCTION)}

Plastik enjeksiyon kalıplama polimer ergiyiğin kalıp boşluğuna belirlenen kalıplama şartlarıyla itildiği ve plastik parça formunda soğutularak katılaştırıldığı bir süreçtir. Enjeksiyon kalıplamanın en önemli avantajı karmaşı geometrili parçaların kolayca kalıplanabilmesidir. Enjeksiyon kalıplama şartları; kalıp sıcaklı̆̆ı, enjeksiyon basıncı, enjeksiyon hızı, enjeksiyon sıcaklığı, ütüleme basıncı ütüleme süresi, soğutma süresi, vb. olarak sıralanabilir. Bu kalıplama şartları optimum olarak verilmezse parçada çarpılma, orantısız çekme, kalıntı gerilme, vb. hatalar oluşur. Huang ve Tai (2001) bir çalışmalarında [1] ütüleme basıncının enjeksiyonla kalıplanmış Polikarbonat/ Akrilonitril bütadien stiren (PC/ABS) karışımı ince cidarlı parçaların çarpılmaları üzerindeki en önemli faktör olduğunu ve bunu kalıp sicaklığı, enjeksiyon sıcaklığı ve ütüleme süresinin takip ettiğini belirtmişlerdir. Kalıplanmış parçalardaki hatalar, kalıplama esnasında birçok faktörün etkisiyle oluşmaktadır. Bu hatalar parçanın ölçüsel kararlılığını 
ve kalitesini etkilemektedir. Kalıntı gerilmelerin tahmin edilmesi için Young (2004) [2] tarafindan teorik bir visko-elastik model, Kabanemi ve ark. (1998) [3] tarafindan da, visko-elastik yaklaşıma sahip başka bir teorik model geliştirilmiştir. Çalışmalarında, simülasyon çalışmaları sonucunda kalıntı gerilmelerin teorik olarak tahmin edilebileceğini belirtmektedirler [2, 3].

Kalıplama şartlarının parçalar üzerindeki etkisini gösteren, Ozcelik ve Erzurumlu (2006)'nun yaptığı bir çalışmada da; ütüleme basıncının, kalıp sıcaklığının, ütüleme süresinin, enjeksiyon sıcaklığının ve soğutma süresinin kalıplanan parçalardaki çarpılmalar üzerinde önemli etkiye sahip olduğu belirtilmektedir [4].

Kalıntı gerilmeler kalıplamanın akış, sıcaklık ve basınç geçmişinin sonucu oluşur ve oluşma nedenlerine göre ikiye ayrılırlar: akış gerilmeleri ve 1sıl gerilmeler. Bunlar, enjeksiyonla kalıplanmış parçalardaki orantısız çekme ve çarpılmaların temel sebepleridir. Kalıntı gerilmeler, kalıplama sırasında kalıp boşluğundaki farklı sıcaklık dağılımı nedeniyle oluşmakta ve parça kalıptan çıkartılıp, ortam sıcaklığına kadar soğutulduğunda da hâlâ parça üzerinde kalmaktadırlar. Kamal ve ark. (2002) [5], enjeksiyon kalıplama esnasında kalıntı gerilmelerin rahatlaması için soğutma hızının önemine değinmişlerdir. Sen ve Bhattacharya (2000) [6] da nişasta ve sentetik polimer karışımlarından kalıplanmış parçalardaki kalıntı gerilmeler üzerine yaptıkları bir çalışmada, enjeksiyon sıcaklığının etkisiz, kalıp sıcaklığının etkili olduğunu ve ütüleme basıncının ütüleme süresine oranla daha etkili olduğunu ifade etmişlerdir. Katmer ve Karataş (2012) [7], enjeksiyonla kalıplanmış polistiren (PS) parçalardaki kalıntı gerilmeler üzerinde en etkili kalıplama şartlarının; enjeksiyon basıncı, kalıp sıcaklığı ve ütüleme süresi olduğunu tespit etmişlerdir.

Kalıntı gerilmelere parça yüzeyinde kalıp sıcaklığı ve ütüleme süresi daha etkinken, parçanın iç kısımlarda ise enjeksiyon basıncı ve kalıp sıcaklığının etkili olduğunu belirtmişlerdir [7].

Katman kaldırma tekniği, düz bir parçanın yüzeyinden ince tabakalar kaldırılması ve katman kaldırma sonrasında kaldırılan tabakadaki gerilme değeriyle orantılı olarak parçanın deforme olması esasına dayanan kalıntı gerilme ölçme yöntemidir. Numune Şekil 1'de görüldüğü gibi katman kaldırma işleminden sonra dairesel şekilde çarpılır ve bu eğilme kaldırılan tabakadaki gerilmenin bir fonksiyonudur.

Eşitlik (1) ve (2) kullanılarak, deformasyon ile kaldırılan katmanın kalıntı gerilme değeri arasında ilişki kurulabilmektedir [8]. Akışa paralel ve dik (x ve y yönü) yönlerdeki gerilmeler eşit kabul edilmiştir.

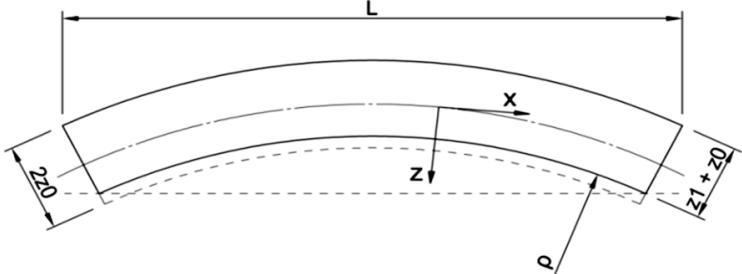

Şekil 1. Eğikliğin ölçümü (Determination of the curvature of a deformed bar)

$\sigma x\left(z_{1}\right)=-E / 6(1-v)\left\{\left(\left(z_{0}+z_{1}\right)^{2} d K x\left(z_{1}\right)\right) /\right.$

$\left.d z_{1}+4\left(z_{0}+z_{1}\right) K x\left(z_{1}\right)-2 \int_{-z 0}^{z 1} K x\left(z_{1}\right) d z\right\}$

$K x=1 / \rho$

Burada, E, elastikiyet modülü, $v$, poisson oran1, $\rho$, numunedeki eğiklik yarıçapı, $L$, bükülmüş numunenin boyudur. $2 Z_{0}$, numune kalınlığını ve $Z_{1}+Z_{0}$, katman kaldırma işleminden sonra kalan kalınlığı ifade eder (Şekil 1).

Kalıplama şartları parçaların mekanik özellikleri üzerinde de etkilidir. Zhou ve Mallick (2005) enjeksiyon sıcaklığı ve ütüleme basıncının, \%40 talk katkılı PP numunelerin çekme ve yorulma dayanımları üzerinde etkili olduğunu belirtilmektedirler [9]. Vianna (2005) kalıplama şartlarının polimerlerin mekanik özellikleri ve morfolojisi üzerine etkilerini araştırmıştır [10]. Çalışmada, enjeksiyon sıcaklığı, kalıp sıcaklığı ve enjeksiyon hızı parametrelerinin PP'nin morfolojisi ve çekme dayanımına etkilerini incelemiştir. PP'nin çekme dayanımı, enjeksiyon sıcaklığı ve enjeksiyon hızının azaltılmasıyla artarken, kalıp sicaklığının düşürülmesiyle de azalmaktadır [10]. Plastik parçaların çekme dayanımı çekme test hızıyla da değişmektedir, yüksek çekme hızlarında random PP daha yüksek çekme dayanımı göstermektedir [11].

$\mathrm{Bu}$ çalışmada, enjeksiyon kalıplama işleminin bütün aşamalarını kapsayan altı kalıplama şartının ve bunların üçer seviyesinin (enjeksiyon basınc1, enjeksiyon sıcaklığı, kalıp sıcaklığı, ütüleme basıncı ve süresi, soğutma süresi), yüksek yoğunluklu polietilen ve polipropilen parçalardaki kalıntı gerilmelere ve çekme dayanımlarına etkisi deneysel olarak araştırılmıştır. Elde edilen sonuçlar üzerinden kalıplanan parçalarda minimum kalıntı gerilme oluşumu için kalıplama şartlarının optimum seviyeleri belirlenmiştir.

\section{DENEYSEL ÇALIŞMA (EXPERIMANTAL STUDY)}

Bu çalışmada Tablo 1'de özellikleri verilen YYPE (PETKIM Petilen YY I668 (UV)) ve PP (PETKIM Petoplen MH 418) malzemeler kullanılmıştır. 100x40x2 $\mathrm{mm}^{3}$ boyutlarında dikdörtgen kesitli plaka şeklinde ve çekme çubuğu (ASTM D638-08 Tip IV) numuneler enjeksiyonla kalıplanmıştır. Kalıplama şartlarının YYPE ve PP parçalardaki kalıntı 
gerilmelere etkilerinin belirlenmesi için Tablo 2'de verilen seviyeler kullanılmıştır. Kalıplama şartlarının alt ve üst sınır değerleri belirlenirken "Arburg Practical Guide to Injection Moulding" kitabındaki değerler esas alınmıştır [12]. Çekme çubuğu 3,2 mm dikdörtgen düz plaka numuneler de $2 \mathrm{~mm}$ et kalınlığındadır. Ayrıca, uygulanan Taguchi Deney Tasarımı, L27 ortogonal dağılım, Tablo 3'te verilmiştir.

Tablo 1. YYPE ve PP Malzemelerin Özellikleri (The properties of materials (PP and HDPE)

\begin{tabular}{lccc}
\hline Özellikler & Birim & YYPE & PP \\
\hline Ergime Akıș İndeksi & $\mathrm{g} / 10$ dak. & $4.5-6.0$ & $4.0-6.0$ \\
Yoğunluk (23 $\left.{ }^{\circ} \mathbf{C}\right)$ & $\mathrm{g} / \mathrm{cm}^{3}$ & $0.963-$ & 0.905 \\
Akmada Çekme Dayanımı & $\mathrm{MPa}$ & 0.967 & 30 \\
Kopmada Çekme Dayanımı & $\mathrm{MPa}$ & 17 & 34 \\
Kopmada Uzama & $\%$ & 1250 & \\
Izod Darbe Dayanımı & $\mathrm{J} / \mathrm{m}$ & 50 & \\
Çevresel Yüzey Çatlağı & $\mathrm{saat}$ & 4 & \\
Elastiklik Modülü (E) & $\mathrm{MPa}$ & 1100 & 1300 \\
Poisson Oranı (v) & - & 0,35 & 0,35 \\
\hline
\end{tabular}

Ütüleme ve soğutma süreleri numunelerin et kalınlıklarına göre Eşitlik 3, 4, ve 5 kullanılarak belirlenmiştir.

$\mathrm{t}_{\mathrm{kn}}=\mathrm{d}(1+2 \mathrm{~d})$

$\mathrm{t}_{\mathrm{n}}=0,3 \mathrm{t}_{\mathrm{kn}}$

$t_{k}=0,7 t_{k n}$

Eşitlik 3'te $t_{\mathrm{kn}}$ soğutma ve ütüleme süresinin toplamını; d, parça et kalınlığını göstermektedir. Eşitlik 4'te $t_{n}$ ütüleme süresini, Eşitlik 5'te de $t_{k}$ kalan soğutma süresini ifade etmektedir.

Tablo 2. Numunelerin kalıplama şartları (The molding conditions of specimens )

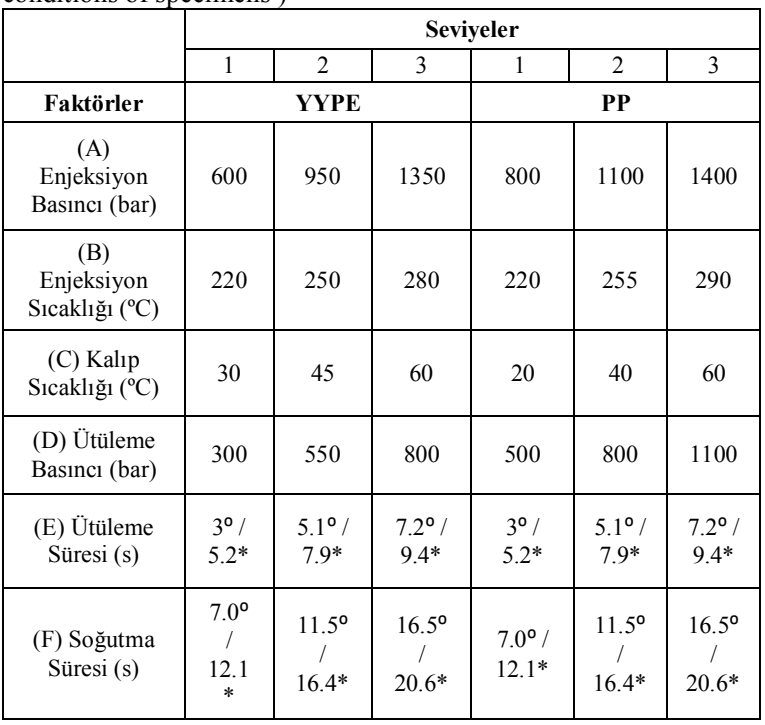

${ }^{0}$ dikdörtgen prizma numuneler için uygulanan ütüleme süresi ve soğutma süresi değerleridir.

* çekme çubuğu numuneler için uygulanan ütüleme süresi ve soğutma süresi değerleridir.
Tablo 3. Taguchi $\mathrm{L}_{27}$ otogonal dağılım deney tasarımı (Taguchi's experiment design ( $\mathrm{L}_{27}$ orthogonal pattern)

\begin{tabular}{lllllll}
\hline No & A & B & C & D & E & F \\
\hline L1 & 1 & 1 & 1 & 1 & 1 & 1 \\
\hline L2 & 1 & 1 & 1 & 1 & 2 & 2 \\
\hline L3 & 1 & 1 & 1 & 1 & 3 & 3 \\
\hline L4 & 1 & 2 & 2 & 2 & 1 & 1 \\
\hline L5 & 1 & 2 & 2 & 2 & 2 & 2 \\
\hline L6 & 1 & 2 & 2 & 2 & 3 & 3 \\
\hline L7 & 1 & 3 & 3 & 3 & 1 & 1 \\
\hline L8 & 1 & 3 & 3 & 3 & 2 & 2 \\
\hline L9 & 1 & 3 & 3 & 3 & 3 & 3 \\
\hline L10 & 2 & 1 & 2 & 3 & 1 & 2 \\
\hline L11 & 2 & 1 & 2 & 3 & 2 & 3 \\
\hline L12 & 2 & 1 & 2 & 3 & 3 & 1 \\
\hline L13 & 2 & 2 & 3 & 1 & 1 & 2 \\
\hline L14 & 2 & 2 & 3 & 1 & 2 & 3 \\
\hline L15 & 2 & 2 & 3 & 1 & 3 & 1 \\
\hline L16 & 2 & 3 & 1 & 2 & 1 & 2 \\
\hline L17 & 2 & 3 & 1 & 2 & 2 & 3 \\
\hline L18 & 2 & 3 & 1 & 2 & 3 & 1 \\
\hline L19 & 3 & 1 & 3 & 2 & 1 & 3 \\
\hline L20 & 3 & 1 & 3 & 2 & 2 & 1 \\
\hline L21 & 3 & 1 & 3 & 2 & 3 & 2 \\
\hline L22 & 3 & 2 & 1 & 3 & 1 & 3 \\
\hline L23 & 3 & 2 & 1 & 3 & 2 & 1 \\
\hline L24 & 3 & 2 & 1 & 3 & 3 & 2 \\
\hline L25 & 3 & 3 & 2 & 1 & 1 & 3 \\
\hline L26 & 3 & 3 & 2 & 1 & 2 & 1 \\
\hline L27 & 3 & 3 & 2 & 1 & 3 & 2 \\
\hline
\end{tabular}

Kalıntı gerilmelerin tespit edilmesi için katman kaldırma işlemi yapılmıştır. Yüzeyden itibaren, parça kalınlığ 1 mm'ye düşene kadar, 0,2 mm kalınlığında tabakalar kaldırılmıștır. Her tabaka kaldırma işleminden sonra numunelerdeki deformasyon fotoğraf tabanlı ölçüm sistemiyle ölçülmüştür. Katmanlardaki ölçülen deformasyon değerleri üzerinden Eşitlik 1 ve 2 kullanılarak, tabakalardaki kalıntı gerilmeler hesaplanmıştır.

\section{SONUÇLAR VE TARTIŞMA (RESULTS AND DISCUSSION)}

\section{Kalınt Gerilmeler}

Kalıntı gerilmeler YYPE ve PP dikdörtgen kesitli numuneler $(100 \times 40 \times 2)$ için kalınlığı 1mm'ye düşene kadar beş katmanda ölçülmüştür. Her iki malzemenin kalıntı gerilme verilerine varyans analizi uygulanmış ve sonuçlar F testi $(\alpha=0,05$; pay serbestlik derecesi $=2$; payda serbestlik derecesi $=26$ değişkenlerine göre standart $F$ değeri; $\quad F_{s}=3,37$ 'dir.) ile değerlendirilmiştir. $F$ değeri, standart $F$ değerinin $\left(F_{s}\right)$ üzerinde bulunan faktörlerin sonuçlar üzerindeki etkisi istatistiksel olarak anlamlıdır ve dikkate alınmalıdırlar.

Tablo 4'te verilmiş olan varyans analizi sonuçlarına göre, soğutma süresi ve enjeksiyon sıcaklığı YYPE (F değerleri sirasıyla: 6,$10 ; 3,72)$ ve PP (F değerleri sırasıyla: 5,$51 ; 4,24)$ parçalardaki kalıntı gerilmeler üzerinde en etkili faktörler bulunmuşlardır. Bunları YYPE'de ütüleme basıncı $(F=3,05)$, PP'de ise kalıp sıcaklığı $(\mathrm{F}=2,87)$ takip etmiştir. Ütüleme basıncı ve kalıp sıcaklığı şartlarının $\mathrm{F}$ değerleri $\mathrm{F}_{\mathrm{s}}$ 'den küçük olmasına rağmen, $F_{s}$ 'ye yakın değerde oldukları için etkileri dikkate alınmıștır. 
Tablo 4. YYPE ve PP kalıntı gerilme Varyans Analizi Sonuçları (Results of ANOVA of residual stresses for HDPE and PP)

\begin{tabular}{|c|c|c|c|c|c|c|c|c|c|c|c|c|c|c|}
\hline Faktör & SD & $\mathrm{F}_{\mathrm{s}}$ & \multicolumn{4}{|c|}{ Yüzey } & \multicolumn{4}{|c|}{ Ara düzlem } & \multicolumn{4}{|c|}{ Çekirdek } \\
\hline \multicolumn{15}{|c|}{ YYPE } \\
\hline (B) & 2 & 3,37 & 6,30 & 3,15 & 0,85 & 0,44 & 0,16 & 0,08 & 3,72 & 0,05 & 0,10 & 0,05 & 1,79 & 0,20 \\
\hline (C) & 2 & 3,37 & 3,40 & 1,70 & 0,46 & 0,63 & 0,01 & 0,00 & 0,23 & 0,79 & 0,06 & 0,03 & 1,04 & 0,38 \\
\hline (F) & 2 & 3,37 & 6,77 & 3,38 & 0,92 & 0,42 & 0,27 & 0,13 & 6,10 & $\mathbf{0 , 0 1}$ & 0,08 & 0,04 & 1,37 & 0,28 \\
\hline Hata & 14 & & 51,6 & 3,96 & & & 0,31 & 0,02 & & & 0,40 & 0,02 & & \\
\hline Toplam & 26 & & 85,1 & & & & 0,91 & & & & 0,95 & & & \\
\hline \multicolumn{15}{|c|}{ PP } \\
\hline (D) & 2 & 3,37 & 1,78 & 0,89 & 1,21 & 0,32 & 0,05 & 0,02 & 0,73 & 0,5 & 0,02 & 0,01 & 0,24 & 0,78 \\
\hline (E) & 2 & 3,37 & 2,18 & 1,09 & 1,48 & 0,26 & 0,04 & 0,02 & 0,61 & 0,56 & 0,04 & 0,02 & 0,43 & 0,66 \\
\hline (F) & 2 & 3,37 & 8,13 & 4,06 & 5,51 & $\mathbf{0 , 0 1}$ & 0,19 & 0,09 & 2,8 & 0,09 & 0,04 & 0,02 & 0,37 & 0,69 \\
\hline Hata & 14 & & 10,3 & 0,73 & & & 0,49 & 0,03 & & & 0,79 & 0,05 & & \\
\hline Toplam & 26 & & 29,0 & & & & 1,36 & & & & 1,10 & & & \\
\hline
\end{tabular}

KT: Kareler Toplamı, KO: Kareler Ortalaması SD: Serbestlik Derecesi, $F_{\mathrm{s}}$ : standart F değeri $(\alpha=0,05$; pay serbestlik derecesi=2, payda serbestlik derecesi = 26) A: Enjeksiyon Basıncı, B:Enjeksiyon Sıcaklığı, C: Kalıp Sıcaklığı, D: Ütüleme Basıncı, E:Ütüleme Süresi, F:Soğutma Süresi

Tablo 4'te soğutma süresi ve enjeksiyon sicaklı̆̆ 1 YYPE parçaların ara düzlemdeki kalıntı gerilmeler üzerinde etkiliyken, ütüleme basıncının çekirdekteki kalıntı gerilmeler üzerinde etkin olduğu belirlenmiştir. PP parçalarda, soğutma süresi yüzeydeki ve ara düzlemdeki kalıntı gerilmeler üzerinde etkili olurken, enjeksiyon sicaklığ 1 ve kalıp sıcaklığının sadece ara düzlemdeki kalıntı gerilmelere etki ettiği tespit edilmiştir.

\section{Çekme Dayanımı}

Çekme testleri sonucunda elde edilen, çekme dayanımı değeri için SN oranları, Taguchi'nin “büyük iyidir (larger is better)" prensibine göre hesaplanmıștır. Sonuçlar, SN oranları üzerinden varyans analizi (ANOVA) ile değerlendirilmiştir
(Tablo 5). F-testi $(\alpha=0,05)$ değerlendirmesiyle faktörlerin önemi tanımlanmıştır. Varyans analizi sonuçlarında ütüleme süresinin $(\mathrm{F}=19,26)$ YYPE parçaların çekme dayanımları üzerinde etkisinin istatistiksel açıdan anlamlı olduğu bulunmuştur. Enjeksiyon sıcaklığının çekme dayanımına etkisi $(\mathrm{F}=2,66) \mathrm{F}$ testi değerlendirmesinde dışarıda kalsa da yakın değerde çıktığı için dikkate alınmıştır. Diğer kalıplama şartları YYPE'nin çekme dayanımı üzerinde etkili bulunmamıştır. PP parçaların çekme dayanımının varyans analizi sonuçları (Tablo 5) incelendiğinde; $\mathrm{F}$ testi $(\alpha=0,05)$ değerlendirme sonuçlarına göre, enjeksiyon sıcaklığı $(\mathrm{F}=108,1)$ ve ütüleme basincı $(\mathrm{F}=37,74)$ parametrelerinin kalıplanmış PP parçaların çekme dayanımı üzerinde etkili olduğu belirlenmiştir.

Tablo 5. YYPE ve PP için çekme dayanımı varyans analizi (ANOVA) sonuçları (Results of ANOVA of yield strength for HDPE and PP)

\begin{tabular}{|c|c|c|c|c|c|c|c|c|c|c|}
\hline \multicolumn{3}{|c|}{ (n) } & \multicolumn{4}{|c|}{$\begin{array}{c}\text { YYPE } \\
\text { Cekme Dayanımı }\end{array}$} & \multicolumn{4}{|c|}{$\begin{array}{c}\text { PP } \\
\text { Cekme Dayanımı }\end{array}$} \\
\hline Faktör & $\begin{array}{l}S \\
D\end{array}$ & $\mathrm{~F}_{\mathrm{s}}$ & KT & $\mathrm{KO}$ & $\mathrm{F}$ & $\mathrm{P}$ & KT & $\mathrm{KO}$ & $\mathrm{F}$ & $\mathrm{P}$ \\
\hline (A) Enj. Bas. & 2 & 3,37 & 0,039 & 0,01 & 0,654 & 0,534 & 0,019 & 0,009 & 1,478 & 0,261 \\
\hline (B) Enj. Sicak. & 2 & 3,37 & 0,160 & 0,08 & 2,668 & 0,104 & 1,391 & 0,695 & 108,1 & 0,000 \\
\hline (C) Kalıp Sicak. & 2 & 3,37 & 0,016 & 0,008 & 0,270 & 0,766 & 0,002 & 0,001 & 0,199 & 0,821 \\
\hline (D) Ütüleme Bas. & 2 & 3,37 & 0,024 & 0,01 & 0,412 & 0,669 & 0,485 & 0,242 & 37,74 & 0,000 \\
\hline (E)Ütüleme $S$. & 2 & 3,37 & 1,143 & 0,57 & 19,261 & 0,0001 & 0,015 & 0,007 & 1,179 & 0,336 \\
\hline (F) Soğut. S. & 2 & 3,37 & 0,062 & 0,03 & 1,037 & 0,380 & 0,001 & 0,000 & 0,092 & 0,912 \\
\hline Hata & 14 & & 0,420 & 0,03 & & & 0,09 & 0,006 & & \\
\hline Toplam & 26 & & 1,866 & & & & 2,005 & & & \\
\hline
\end{tabular}

KT: Kareler Toplamı, KO: Kareler Ortalaması SD: Serbestlik Derecesi, $F_{s}$ : standart F değeri $(\alpha=0,05$; pay serbestlik derecesi $=2$, payda serbestlik derecesi = 26) A: Enjeksiyon Basıncı, B:Enjeksiyon Sıcaklı̆̆ı, C: Kalıp Sıcaklı̆̆ı, D: Ütüleme Basıncı, E:Ütüleme Süresi, F:Soğutma Süresi 
Burada, YYPE ve PP parçaların kalıntı gerilmeleri üzerinde etkili bulunan; soğutma süresi, enjeksiyon sıcaklığı, ütüleme basıncı, ütüleme süresi ve kalıp sıcaklığı şartlarının etkileri detaylı olarak incelenmiştir. Ayrıca YYPE ve PP parçaların çekme dayanımlarında etkili olan enjeksiyon sıcaklı̆̆ı, ütüleme basıncı ve ütüleme süresi şartları incelenirken kalıntı gerilmeleriyle olan ilişkisi de incelenmiştir.

\subsection{Soğutma Süresinin Etkisi (Effects of Cooling Time)}

PP ve YYPE parçalarda farklı soğutma sürelerinde (7 $\mathrm{s}, 11,5 \mathrm{~s}$ ve $16,5 \mathrm{~s})$ oluşan kalıntı gerilme grafikleri Şekil 2'de verilmiştir. Soğutma süresi enjeksiyonla kalıplanmış PP ve YYPE parçalardaki kalıntı gerilmeler üzerinde en etkili faktör bulunmuştur. PP parça yüzeyinde $7 \mathrm{~s}$ 'lik soğutma süresinde basma kalıntı gerilmesi, 11,5 s ve 16,5 s soğutma sürelerinde ise çekme kalıntı gerilmesi oluşmuştur. YYPE parçaların yüzeyinde ise soğutma süresinin üç seviyesinde de çekme kalıntı gerilmesi oluşmuştur (Şekil 2). Yüzey bölgesinde en düşük kalıntı gerilmenin $16,5 \mathrm{~s}$ soğutma süresinde oluştuğu görülmektedir. Kalınlık boyunca soğutma süresiyle kalıntı gerilme dağılımları incelendiğinde, toplam kalıntı gerilmenin, 16,5s soğutma süresinde en düşük, $7 \mathrm{~s}$ 'de de en yüksek gerçekleştiği bulunmuştur. Soğutma süresinin her iki malzemenin çekme dayanımı üzerinde etkili olmadığı varyans analizi sonuçlarıyla açıklanmıştı (Tablo 5). Deneylerden edinilen sonuçlara göre, daha düşük kalıntı gerilmeli parçalar kalıplamak için, YYPE malzemede uzun soğutma süresi, PP malzemede de yüzeyde basma kalıntı gerilmesinin oluştuğu düşük seviye soğutma süresi optimum değerdir. Yüzeyde basma kalıntı gerilmesi parçaların yüzey çatlaklarına karşı korunmasında ve yorulma dayanımının artmasında olumlu rol oynamaktadır $[13,14]$.

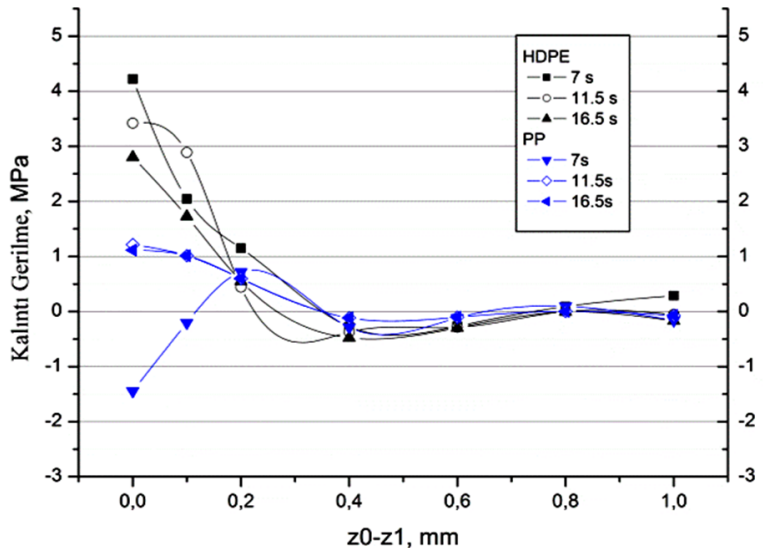

Şekil 2. YYPE ve PP için soğutma süresinin etkisi (Effect of cooling time for HDPE and PP)

\subsection{Enjeksiyon Sıcaklığının Etkisi (Effects of Melt Temperature)}

Enjeksiyon sıcaklığı, PP ve YYPE parçalardaki kalıntı gerilmeler üzerinde ikinci etkili kalıplama şartı olmuştur. Farklı enjeksiyon sıcaklıklarında parçalarda oluşan kalıntı gerilme grafikleri Şekil 3'te görülmektedir. Enjeksiyon sıcaklığı $220^{\circ} \mathrm{C}$ 'den $280^{\circ} \mathrm{C}^{\prime}$ ye arttırıldığında YYPE parçaların yüzeyindeki kalıntı gerilmeler 4,25 MPa'dan 2,35 MPa'ya düşmüştür. PP parçalarda da enjeksiyon sıcaklığı artırıldığında yüzeydeki çekme gerilmeleri azalmış ve enjeksiyon sıcaklığının en yüksek seviyesinde basma gerilmesine dönmüştür. Yarı-kristal yapıdaki YYPE ve PP malzemeler için sıcaklık ve soğumanın dolayısıyla sürenin kristalleşme için önemli olduğu bilinmektedir. Bu çalışmadan da elde edilen sonuçlar, yüksek enjeksiyon sıcaklığında, kalıntı gerilmenin daha düşük değerlerde oluştuğunu göstermiştir. Buradan, malzemenin optimum veya optimuma yakın molekül düzenlenmesinin sağlanarak kalıplama esnasında oluşan gerilmelerin rahatladığı sonucu çıkartılmıştır.

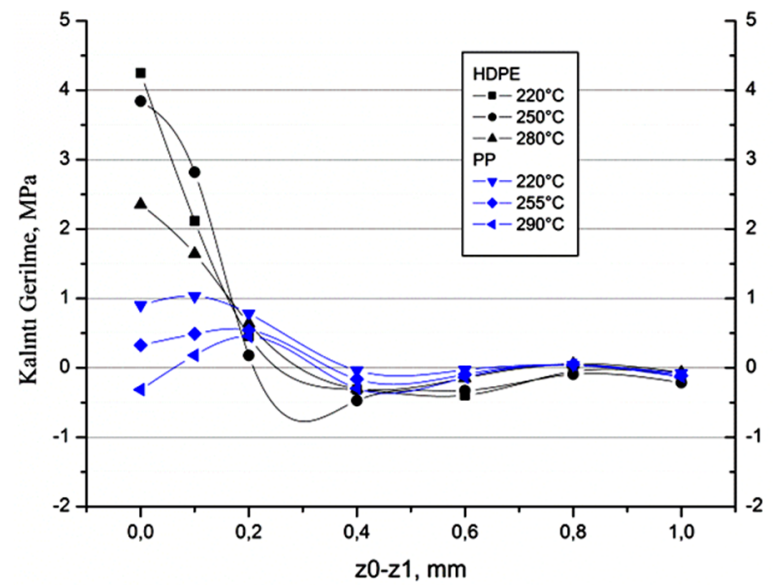

Şekil 3. YYPE ve PP için enjeksiyon sıcaklığının etkisi (The effect of melt temperatures for HDPE and PP)

Şekil 4'te enjeksiyon sıcaklığının YYPE ve PP parçaların yüzey bölgesindeki kalıntı gerilme değerleriyle, aynı malzemelerin çekme dayanımı değerlerinin karşılaştırılması yapılmıştır. $\mathrm{Bu}$ şekil incelendiğinde, artan enjeksiyon sıcaklığıyla, çekme dayanımlarının azaldığı görülmektedir.

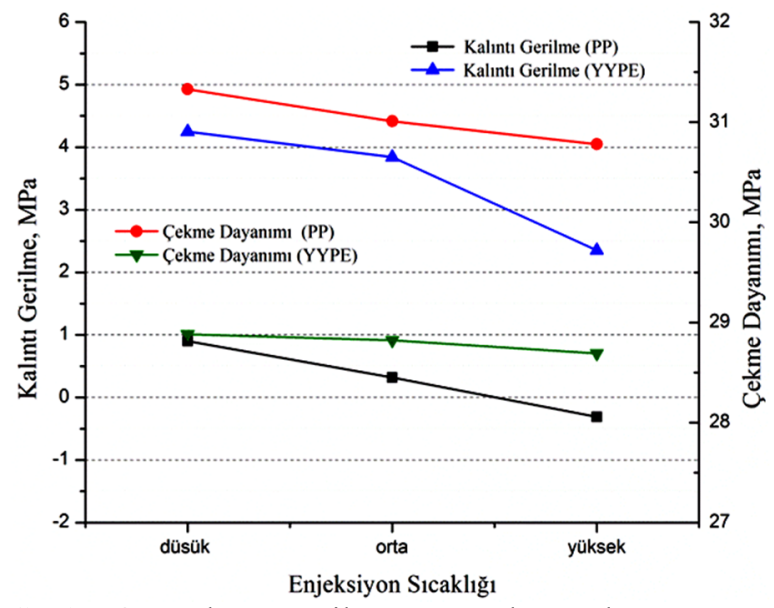

Şekil 4. Kalıntı gerilme ve çekme dayanımının enjeksiyon sıcaklığıyla değişimi (Melt temperature vs. residual stress, and tensile strength) 
YYPE malzemede yüksek enjeksiyon sicaklığı yüzeydeki kalıntı gerilmeleri büyük ölçüde azaltırken, çekme dayanımını da biraz düşürmüştür. PP malzemede ise, yüksek enjeksiyon sicaklığ edilen yüzeyde basma kalıntı gerilmesi oluşturmasına rağmen, çekme dayanımı yaklaşık $1 \mathrm{MPa} l 1 \mathrm{k}$ düşüş göstermiştir.

Wang ve Young (2005) simülasyon çalışmalarında iki ayrı modelden (elastik ve viskoelastik) elde edilen sonuçlarla enjeksiyon sıcaklığının artırılmasıyla yüzeydeki çekme kalıntı gerilmelerini azalttığını ifade etmektedirler [15]. Sen ve Bhattacharya (2000) enjeksiyon sıcaklığının kalıntı gerilmelere etki etmediğini belirtmektedir [6]. PS parçalar üzerine olan çalışmamızda [7], enjeksiyon sıcaklığı kalıntı gerilme üzerinde etkin bulunmazken, bu çalışmada her iki malzeme üzerinde de en etkili faktör bulunmuştur. $\mathrm{Bu}$, YYPE ve PP malzemelerin yarı kristalin içyapısı nedeniyle yüksek sıcaklıkta daha düzenli moleküler yapı oluşmasının, dolayısıyla gerilim rahatlamasının bir sonucudur.

\section{3 Ütüleme Basıncının Etkisi (Effects of Packing Pressure)}

YYPE’yle kalıplanmış parçalarda ütüleme basıncı (300, 550, 800 bar) kalıntı gerilmeler üzerinde üçüncü düzeyde etkili faktör bulunmuştur. Şekil 5'te farklı ütüleme basınçlarında, YYPE parçalarda ölçülen kalıntı gerilme grafikleri verilmiştir. Grafiklerden, ütüleme basıncı artırıldıkça kalınlık boyunca toplam çekme kalıntı gerilmesinin azaldığı anlaşılmaktadır. Ayrıca, ütüleme basıncı YYPE parçaların çekme dayanımı üzerinde etkili bulunmamıştır (Şekil 6).

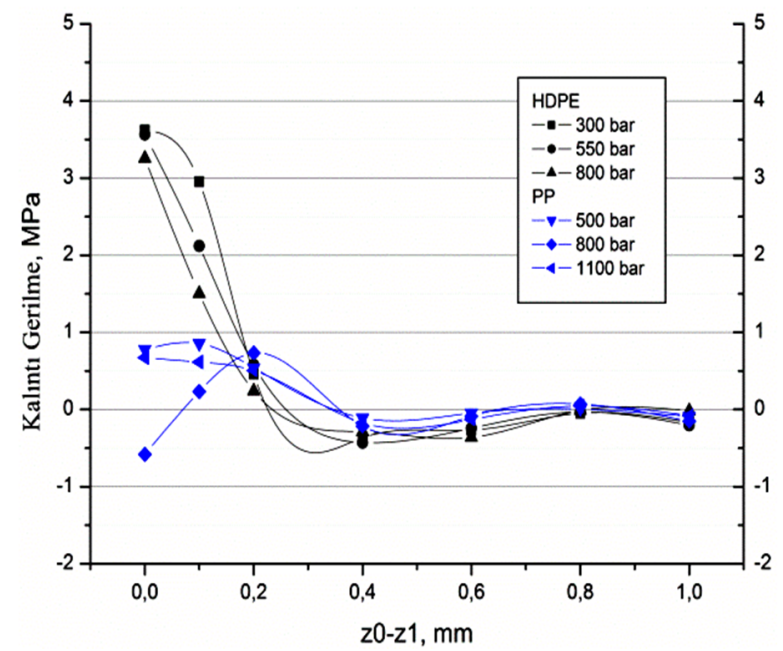

Şekil 5. YYPE ve PP için ütüleme basıncının etkisi (Effects of packing pressure for HDPE and PP)

PP parçalar üzerinde ütüleme basıncının (500, 800, 1100 bar) etkisi önemsiz bulunmuştur. Fakat PP parçaların çekme dayanımları üzerin en etkili ikinci kalıplama şartı ütüleme basıncı olmuştur (Tablo 5).
Ütüleme basıncıyla, kalıntı gerilme ve çekme dayanımı karşılaştırma grafikleri Şekil 6'da verilmiştir. Şekilde PP parçaların ütüleme basıncının artırılmasıyla çekme dayanımını arttırdığı ve bununla birlikte yüzeydeki kalıntı gerilmelerin sırasıyla çekme-basma-çekme olarak değiştiği anlaşılmaktadır.

Zoetelief ve ark. (1996) yüzeydeki çekme kalıntı gerilmelerinin yüksek ütüleme basıncın etkisiyle oluştuğunu ifade etmektedirler [16]. Huang ve Tai (2001) yüksek ütüleme basıncında kalıplanan parçalarda çarpılmanın arttığını belirtmektedirler [1]. Sen ve Bhattacharya (2000) da ütüleme basincinın ütüleme süresine oranla kalıntı gerilmeler üzerinde daha fazla etkili olduğunu belirtmektedirler [6]. Bu çalışmada da ütüleme basıncı YYPE parçaların kalıntı gerilmeleri üzerinde etkili bulunmuşken çekme dayanımları üzerinde etkisiz bulunmuştur. PP parçalar için bu durum tam tersidir; ütüleme basıncı kalıntı gerilmelere etki etmezken, çekme dayanımı üzerinde etkili olmuştur.

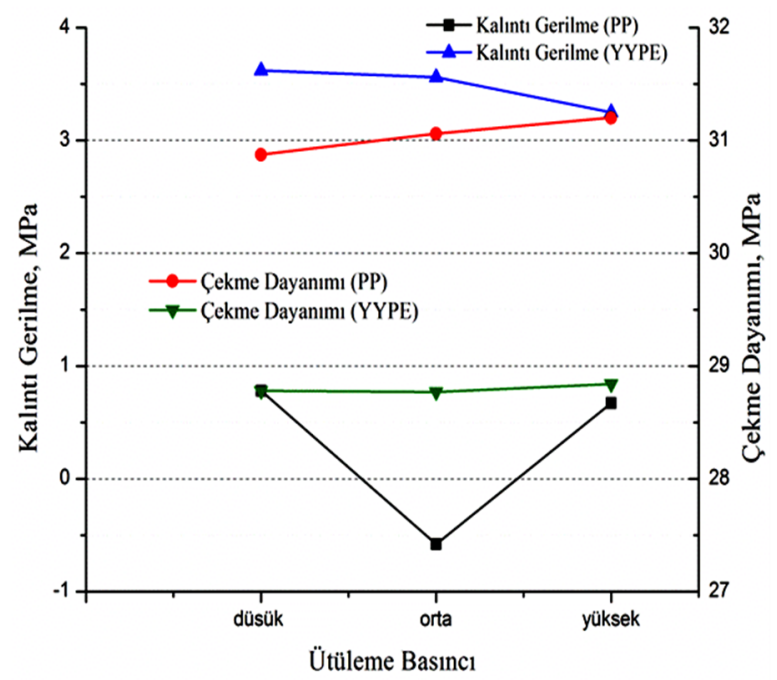

Şekil 6. Kalıntı gerilme ve çekme dayanımının ütüleme basıncıyla değişimi (Packing pressure vs. residual stress and tensile strength)

\section{4 Ütüleme Süresinin Etkisi (Effects of Packing Time)}

Ütüleme süresi enjeksiyonla kalıplanmış YYPE parçalardaki kalıntı gerilmeler üzerinde etkili olmazken (Şekil 7), çekme dayanımı üzerinde en etkili faktör bulunmuştur (Tablo 5). Ütüleme süresinin artırılmasıyla YYPE parçaların çekme dayanımının $\operatorname{arttığı~tespit~edilmiştir~(Şekil~8).~}$

PP parçalardaki kalıntı gerilmeler üzerinde, ütüleme süresinin etkisi incelendiğinde (Şekil 7), 3 s ütüleme süresinde yüzeyde basma gerilmesinin oluştuğu, 5,1 s ve 7,2 s ütüleme sürelerinde bunun çekme gerilmesine döndüğü görülmektedir. Ütüleme süresinin PP parçaların çekme dayanımı üzerinde etkisiz olduğu varyans analizi sonucunda anlaşılmıştır (Tablo 5). 


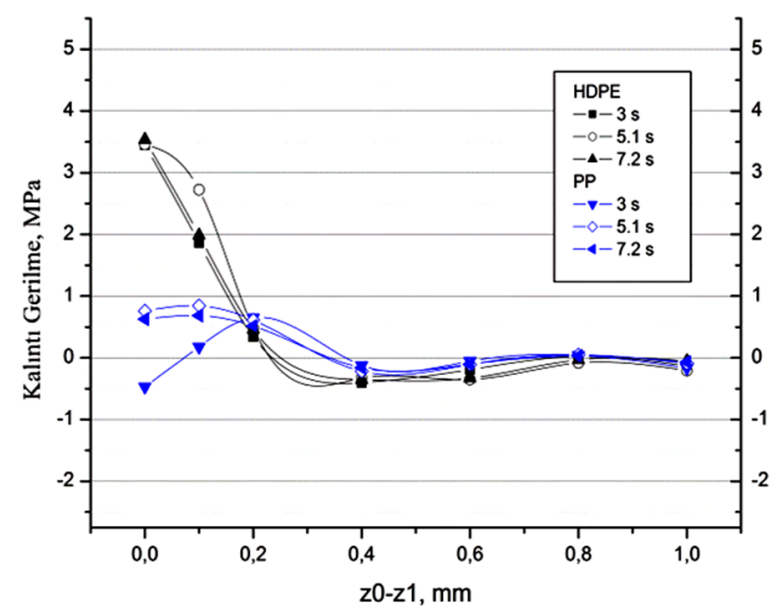

Şekil 7. YYPE ve PP için ütüleme süresinin etkisi (Effects of packing time for HDPE and PP)

Kalıntı gerilme ve çekme dayanımı sonuçları birlikte değerlendirildiğinde, PP parçaların kalıplanmasında düşük ütüleme süresinin kullanılması daha uygun olduğu görülmektedir. (Şekil 8). YYPE malzeme için ise, grafiklerine göre, parçaların kalıplanmasında yüksek ütüleme süresi uygulanması kalıntı gerilmeleri etkilemeden çekme dayanımını artıracağı için daha uygun olmaktadır (Şekil 8).

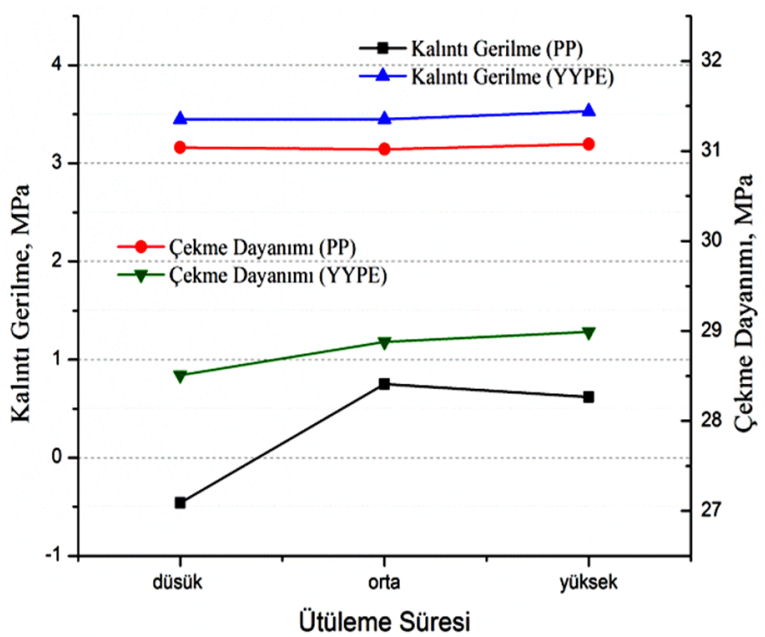

Şekil 8. Kalıntı gerilme ve çekme dayanımının ütüleme süresiyle değişimi (Packing time vs. residual stress and tensile strength)

\subsection{Kalıp Sıcaklığının Etkisi (Effects of Mold Temperature)}

Enjeksiyonla kalıplanmış PP parçalardaki kalıntı gerilmeler üzerinde etkili olan üçüncü kalıplama şartı kalıp sıcaklığı $\left(20,40\right.$ ve $\left.60^{\circ} \mathrm{C}\right)$ olmuştur. Varyans analizi sonuçlarından, ara yüzeydeki kalıntı gerilmelerin kalıp sicaklı̆ı̆ının değişiminden etkilendiği tespit edilmiştir. Şekil 9'daki PP grafikleri incelendiğinde, düşük seviye olan $20^{\circ} \mathrm{C}$ kalıp sıcaklığında, kalınlık boyunca toplam çekme kalıntı gerilmesinin diğer seviyelerde gerçekleşen toplam çekme kalıntı gerilmelerine kıyasla daha az olduğu anlaşılmaktadır. Yüksek kalıp sıcaklığında yüzeyde oluşan çekme gerilmesi daha yüksek iken, kalınlık boyunca gerçekleşen gerilme dağılımı orta seviye kalıp sıcaklığında oluşan kalıntı gerilme dağıılımından daha düşük olmuştur.

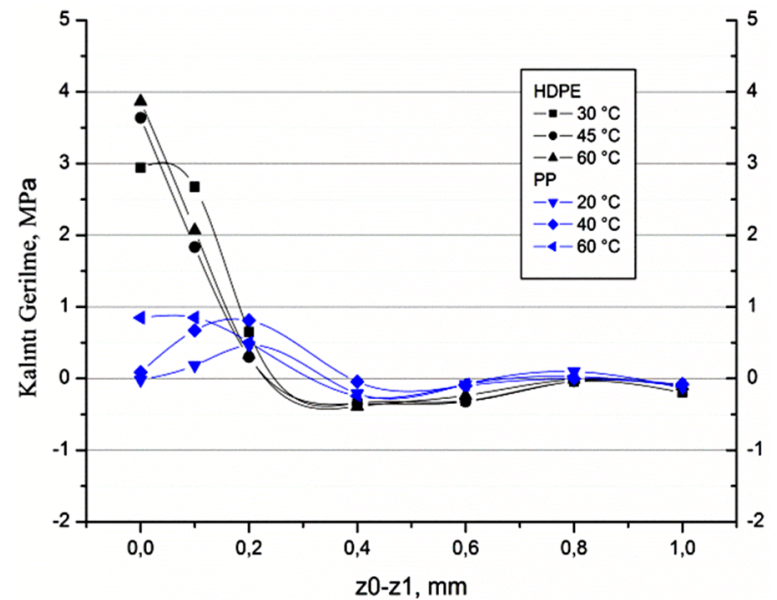

Şekil 9. YYPE ve PP için kalıp sıcaklığının etkisi (Effects of mold temperature for HDPE and PP)

YYPE parçalar üzerinde kalıp sıcaklığının etkisi istatistiksel olarak önemsiz bulunmuş olsa da, Şekil 9'daki grafiklerde, yüzeydeki çekme kalıntı gerilmelerinin düşük kalıp sıcaklığında daha düşük, ara bölgedeki kalıntı gerilmelerin, orta seviye $\left(45^{\circ} \mathrm{C}\right)$ kalıp sıcaklığında daha düşük değerlerde olduğu tespit edilmiştir.

Sen ve Bhattacharya kalıp sıcaklığının artırılmasının nişasta/sentetik polyester (yarı-kristal yapıda) karışımı parçaların yüzeyindeki basma ve içteki çekme kalıntı gerilmelerini azalttığını belirtmektedir. Bunun sebebi olarak, yüksek kalıp sıcaklığında parçanın kalıpta soğuma oranının düşmesi ve dişarıda serbest halde soğumasıyla, gerilme rahatlamasının gerçekleşmesi olduğunu ifade etmektedirler [6]. Katmer ve Karataş (2012) ve Weng ve ark. (2009) da kalıntı gerilmeler üzerinde kalıp sıcaklığının etkili olduğunu, kalıp sıcaklığının artırılmasıyla kalıntı gerilmelerin, azaldığını belirtmektedirler [7, 17]. Deney parçalarının kalın olması $(10 \mathrm{~mm})$, polimere katılan nișasta dolgu [6] ve malzemelerin yapısal farklılıkları [7, 17] aradaki farkın sebebi olarak görülmüştür. Wang ve Young (2005) simülasyon çalışmalarında; elastik modelde parçaların yüzeyinde, kalıp sıcaklığının yüksek seviyesinde çekme, düşük seviyesinde basma ve orta seviyede sıfira yakın kalıntı gerilme oluştuğunu, viskoelastik modelde ise kalıp sıcaklığı arttıkça yüzeydeki çekme gerilmesinin azaldığını belirtmişlerdir [15].

\subsection{Kalıntı Gerilme Dağılımı (The Residual Stress Distribution)}

27 deneyden elde edilen ortalama kalıntı gerilme grafikleri Şekil 10 'da verilmiştir. Şekilde görüldüğü gibi YYPE parçada kalıntı gerilme değerleri 3,5 MPa çekme ve $-0,36 \mathrm{MPa}$ basma aralığında değişmektedir 
ve gerilmeler iki bölgeye ayrılmaktadır: yüzeyde çekme kalıntı gerilmesi ve çekirdekte basma kalıntı gerilmesidir. PP numunelerde ise kalıntı gerilme dağılımı 0,6 MPa çekme ile -0,16 MPa basma aralığındadır ve yüzeyden itibaren sırasıyla çekmebasma-çekme-basma gerilmeleri olarak dağılmıştır.

Kamal ve ark. (2002) YYPE parçalardaki kalıntı gerilme dağılımları üzerine yaptıkları araştırmada, YYPE parçalardaki kalıntı gerilme dağılımının, yüzeyden çekirdeğe doğru sirasıyla çekme-basmaçekme kalıntı gerilmesi olarak dağıldığını belirtmektedirler [5]. YYPE ve PP parçalardaki kalıntı gerilme değerleri, daha önceki çalışmamızdaki polistiren (PS) parçaların kalıntı gerilme değerlerine (4,6 $\mathrm{MPa}$ - (-2 MPa)) oranla, daha düşük çıkmıştır (Katmer ve Karataş, 2012 [7]). PS, YYPE ve PP malzemeler birbirleriyle kıyaslandığında, $P P$ ve YYPE parçalar kalıptan alındıktan sonra PS parçalara oranla daha fazla çarpıldıkları gözlenmiştir. Ancak, en fazla PP parçalar çarpılmıştır. Bu da YYPE ve PP'deki kalıntı gerilmelerin çarpılma ile rahatladığını göstermektedir. Dolayısıyla kalıntı gerilme değerleri de PS'ye göre düşük çıkmıştır.

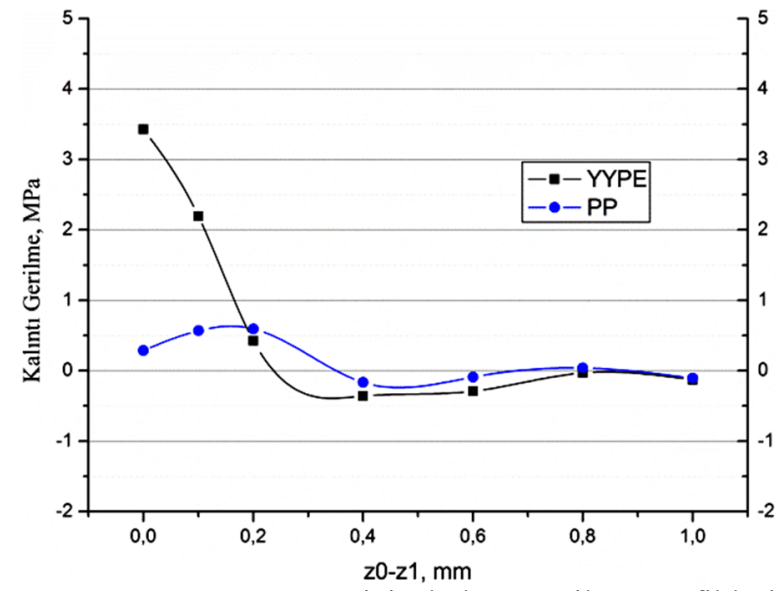

Şekil 10. YYPE ve PP için kalıntı gerilme grafikleri (The mean of plots of residual stress for HDPE and PP)

\section{SONUÇLAR (CONCLUSIONS)}

Sonuçlar, YYPE parçalar üzerinde etkili olan kalıplama şartlarının kalıntı gerilme açısından sırasıyla; soğutma süresi, enjeksiyon sıcaklığı ve kalıp sıcaklığı, çekme dayanımı açısından sırasıyla; ütüleme süresi ve enjeksiyon sicaklığı olduğunu göstermiştir. Enjeksiyon sıcaklığı her iki değer üzerinde de etkili olma yönünden önemli bulunmuştur. Yüksek enjeksiyon sicaklığında, parçalardaki kalıntı gerilmeler azalırken, parçaların çekme dayanımları da azalmıştır. Soğutma süresi ve kalıp sıcaklığı parçaların yüzeyindeki kalıntı gerilmelere etki ederken, çekme dayanımına etki etmemiştir. Ütüleme süresi artırılırken parçaların çekme dayanımı artış göstermiş, kalıntı gerilmelerde önemli bir değişim olmamıştır. YYPE parçalar için kalıntı gerilme ve çekme dayanımı arasında kesin bir ilişki kurulamamıştır.

PP parçalardaki kalıntı gerilmeler üzerinde etkili olan faktörler sırasıyla; soğutma süresi, enjeksiyon sıcaklığı ve kalıp sıcaklığı, çekme dayanımı üzerinde ise en etkili faktörler sırasıyla; enjeksiyon sıcaklığı ve ütüleme basınc1 bulunmuştur. Sadece enjeksiyon sıcaklığı şartı iki özelliğe de etki etmiştir. Soğutma süresi ve kalıp sıcaklığı PP parçalardaki kalıntı gerilmeleri etkilerken, çekme dayanımına etkisiz bulunmuşlardır. Ütüleme basıncının artırılmasıyla çekme dayanımı artarken, sadece orta seviyesinde parça yüzeyinde basma kalıntı gerilmesi tespit edilmiştir. Parçaların yüzeyinde basma kalıntı gerilmesinin oluştuğu seviyeler diğer kalıplama şartları için de dikkate alınmalıdır.

\section{SEMBOLLER (NOMENCLATURE)}

L: $\quad$ bükülmüş numunenin boyu

$\rho: \quad$ numunedeki eğiklik yarıçapı

$\Phi$ : katman kaldırılmış yüzeyin tepe noktasının, düzleme uzaklığı

E: $\quad$ Elastikiyet modülü

$v$ : $\quad$ Poisson oranı

SD: $\quad$ serbestlik derecesi

KT: $\quad$ kareler toplamı

$\mathrm{KO}$ : kareler ortalaması

$F_{\mathrm{s}}$ : $\quad$ standart $\mathrm{F}$ değeri $(\alpha=0,05$; pay serbestlik derecesi $=2$, payda serbestlik derecesi $=26$ )

\section{TEŞEKKÜR (ACKNOWLEDGEMENT)}

$\mathrm{Bu}$ çalışma Gazi Üniversitesi Bilimsel Araştırma Projeleri Birimi tarafindan desteklenmiştir (Proje Numaras1: 07/2009-07).

\section{KAYNAKLAR (REFERENCES)}

1. Huang, M.C., Tai, C.C., "The Effective Factors in the Warpage Problem of an Injection-Molded Part with a Thin Shell Feature", Journal of Material Processing Technology, Cilt 110, No 1, 1-9, 2001.

2. Young, W.B., "Residual stress induced by solidification of thermoviscoelastic melts in the postfilling stage", Journal of Materials Processing Technology, Cilt 145, No 3, 317324, 2004.

3. Kabanemi, K.K., Vaillancourt, H., Wang, H., Salloum, G., "Residual Stresses, Shrinkage, and Warpage of Complex Injection Molded Products: Numerical Simulation and ExperimentaI Validation", Polymer Engineering and Science, Cilt 38, No 1, 21-37, 1998.

4. Ozcelik, B., Erzurumlu, T., "Comparison of the Warpage Optimization in the Plastic Injection Molding Using ANOVA, Neural Network Model and Genetic Algorithm", Journal Material 
Processing Technology, Cilt 171, No 3, 437445, 2006.

5. Kamal, M.R., Lai-Fook, R.A., HernandezAguilar, J.R., "Residual Thermal Stresses in Injection Moldings of Thermoplastics: A Theoretical and Experimental Study", Polymer Engineering and Science, Cilt 42, No 5, 10981114, 2002.

6. Sen, A., Bhattacharya M., "Residual Stresses and Density Gradient in Injection Molded Starch/Synthetic Polymer Blends", Polymer, Cilt 41, No 26, 9177-9190, 2001.

7. Katmer, Ş., Karataş, Ç., "The Effects of Molding Conditions on the Residual Stresses in Injection Molded Polystyrene Flat Parts", Journal of the Faculty of Engineering and Architecture of Gazi University, Cilt 27, No 3, 501-507, 2012.

8. Isayev, A.I., "Orientation, Residual Stresses, and Volumetric Effects in Injection Molding", "Injection and Compression Molding Fundamentals", Cilt 15, Editör: Isayev, A.I., Marcel Dekker Inc., New York, A.B.D, 227-329, 1987.

9. Zhou, Y., Mallick, P.K., "Effects of Melt Temperature and Hold Pressure on the Tensile and Fatigue Properties of an Injection Moulded Talc-Filled Polypropylene", Polymer Engineering and Science, Cilt 45, No 6, 755763, 2005.

10. Vianna, J.C., "Structural interpretation of the strain-rate, temperature and morphology dependence of the yield stress of injection moulded semicrystalline polymers", Polymer, Cilt 46, No 25, 11773-11785, 2005.

11. Sahin, S., Yayla, P., "Effects of testing parameters on the mechanical properties of polypropylene random copolymer", Polymer Testing, Cilt 24, No 5, 613-619, 2005.

12. Goodship, V., "Arburg Practical Guide to Injection Moulding”, Smithers Rapra Technology, Shrewsbury, İngiltere, 2004.

13. Dülek, E., Orman, Ş., Karataş, Ç., Sarıtaş, S., "Bilyali dövme parametrelerinin Ç 1020 çeliğinin yorulma dayanımına etkisi ve oluşan kalıcı gerilmenin katman kaldırma yöntemi ile araştırılması", Journal of the Faculty of Engineering and Architecture of Gazi University, Cilt 20, No 3, 289-295, 2005.

14. Kafkas, F., Karataş, Ç., Sarıtaş, S., "Effect of heat treatment conditions and densities on residual stresses at Hybrid (FLN2-4405) P/M steels", Material Science Forum, Cilt 534-536, 669-672, 2007.

15. Wang, T.H., Young, W.B., "Study on residual stresses of thin-walled injection molding", European Polymer Journal, Cilt 41, No 10, 2511-2517, 2005.

16. Zoetelief, W.F., Douven, L.F.A., Ingen Housz, A.J., "Residual Thermal Stresses in Injection Molded Products", Polymer Engineering and Science, Cilt 36, No 14, 1886-1896, 1996.

17. Weng, C., Lee, W.B., To, S., "Birefringence techniques for the characterization of residual stresses in injection-moulded micro-lens arrays", Polymer Testing, Cilt 28, No 7, 709-714, 2009. 
